\title{
Treatment of Pulmonary Arterial Hypertension Using Initial Combination Therapy of Bosentan and Iloprost
}

\author{
Xinpeng Han MD, Yuhai Zhang PhD, Liang Dong MD, Liying Fang MD, Yaqin Chai MD, \\ Mengjie Niu MD, Yongping Yu MD, Lingli Liu MD, Xuemin Yang MD, Shuoyao Qu MD PhD, \\ and Shengqing $\mathrm{Li} \mathrm{MD} \mathrm{PhD}$
}

\begin{abstract}
BACKGROUND: Monotherapy and sequential combination therapy have been widely used in the treatment of pulmonary arterial hypertension $(\mathrm{PAH})$. There is limited evidence for initial combination therapy in patients with PAH, particularly those with World Health Organization (WHO) functional class III or IV. METHODS: Twenty-seven consecutive treatment-naive PAH subjects with WHO functional class III or IV PAH were randomized into 3 groups with a 1:1:1 ratio: a combination therapy group with $125 \mathrm{mg}$ of bosentan twice daily plus $10 \mu \mathrm{g}$ of iloprost 4-6 times/d; a bosentan monotherapy group with $125 \mathrm{mg}$ of bosentan twice daily; and a iloprost monotherapy group with $10 \mu \mathrm{g}$ of iloprost 4-6 times/d. Clinical and hemodynamic data were collected at baseline, 6 weeks, and 3 months. The primary end point was the change in the 6-min walk distance (6MWD) from baseline values. RESULTS: At baseline, there were no differences in demographics, WHO classification, hemodynamics, classification of PAH, or 6MWD among the 3 groups. The 6MWD significantly improved in the combination therapy group compared with the bosentan monotherapy and iloprost monotherapy groups at week 6 $(P=.001)$ and after 3 months $(P<.001)$, respectively. Secondary end points significantly improved in the combination therapy group for mean pulmonary artery pressure, cardiac index, and WHO functional classification after 3 months of treatment and for $\mathrm{N}$-terminal pro-brain natriuretic peptide, Minnesota Living with Heart Failure questionnaire scores, and $P_{a_{2} 2}$ after 6 weeks and 3 months of treatment, compared with the monotherapy groups. CONCLUSIONS: Initial combination therapy in treatment-naive PAH subjects with WHO functional class III or IV can significantly improve 6MWD, hemodynamics, and quality of life compared with monotherapy. Further studies with large samples and placebo controls are required to assess the tolerability and efficacy of initial combination therapy in patients with PAH. (ClinicalTrials.gov registration NCT01712997). Key words: pulmonary arterial hypertension; combination therapy; bosentan; iloprost; 6-min walk distance. [Respir Care 2017;62(4):489-496. (C) 2017 Daedalus Enterprises]
\end{abstract}

\section{Introduction}

Pulmonary arterial hypertension (PAH) is a chronic, progressive disease of the pulmonary vasculature resulting in poor outcomes if untreated. Management of group 1 PAH has included the use of prostanoids, endothelin receptor antagonists, and phosphodiesterase- 5 inhibitors that

\footnotetext{
This work was supported by National Natural Science Foundation Grants 30871113, 81272586, and 81470249. The authors have disclosed no conflicts of interest.

Drs Han, Zhang, and Dong contributed equally to this work.

Correspondence: Shengqing Li MD PhD, Department of Respiratory Medicine, Huashan Hospital, Fudan University, Shanghai 200040, China. E-mail: shengqingli@hotmail.com.
}

DOI: $10.4187 /$ respcare.05280 
target the prostacyclin receptor, endothelin-1 receptor, and nitric oxide signaling pathway. ${ }^{1-4}$ During recent years, riociguat, a soluble guanylate cyclase stimulator, and selexipeg, a first-in-class, orally available, selective, non-prostanoid prostacyclin receptor (IP) agonist, have been used in the treatment of PAH. ${ }^{5,6}$ The aforementioned pharmacotherapeutic agents have resulted in improved prognosis and quality of life but have also increased the complexity of decision making in treatment. ${ }^{7}$ Monotherapy is the most widely used treatment regimen in PAH. Combination therapy is usually recommended in current treatment guidelines for patients who demonstrate an inadequate clinical response or who deteriorate during monotherapy. ${ }^{8}$ Data from the REVEAL registry suggest that combination therapy is used in $>50 \%$ of patients with pulmonary hypertension in the United States. ${ }^{9}$ Combination therapy is classified as "sequential add-on" combination therapy and "first-line upfront" combination therapy. In the sequential add-on approach, the patient is initially administered a single drug, and, if the patient's condition deteriorates, a second or third drug is administered. ${ }^{10-13}$ Data from randomized controlled trials on sequential combination therapy have particularly grown in recent years, resulting in a change in the level of recommendations in the latest update to the PAH treatment algorithm. ${ }^{8,14}$ In first-line upfront combination therapy, patients with $\mathrm{PAH}$ receive double or triple drug therapy at the commencement of treatment. The AMBITION study was the first to investigate upfront combination therapy in PAH using ambrisentan and tadalafil. ${ }^{15}$ The authors concluded that initial combination therapy with ambrisentan and tadalafil in subjects with $\mathrm{PAH}$ resulted in a significantly lower risk of clinical failure events than ambrisentan or tadalafil monotherapy. ${ }^{15}$ To increase the recommended level of first-line upfront combination therapy, particularly in patients with World Health Organization (WHO) functional class III or IV, validation of the efficacy and safety of other first-line upfront combination therapies is required. This randomized study was performed to compare the efficacy of initial combination therapy using bosentan and iloprost with individual monotherapy in the treatment of PAH.

\section{Methods}

\section{Design and Overview}

This study was a multi-center, randomized, open-label, phase- 3 trial. The study was conducted between October 2012 and December 2015 at 4 different centers in Xi'an, China. The trial protocol was designed by the authors and statisticians.

The study was approved by the institutional review board at each center. All participants provided written informed consent. The study drugs were provided by Actelion Phar-

\section{QUICK LOOK}

\section{Current knowledge}

Pulmonary arterial hypertension (PAH) is a chronic, progressive disease of the pulmonary vasculature resulting in poor outcomes if untreated. Monotherapy and sequential combination therapy have been widely used in the treatment of PAH. There is limited evidence for initial combination therapy in patients with PAH, particularly those with World Health Organization (WHO) functional class III or IV.

\section{What this paper contributes to our knowledge}

First-line upfront combination therapy using bosentan and iloprost in PAH subjects with WHO functional class III or IV significantly improved 6MWD, hemodynamics, and quality of life compared with monotherapy comprising bosentan or iloprost.

maceuticals Ltd (Allschwil, Switzerland) (bosentan) and Bayer (Leverkusen, Germany) (iloprost).

\section{Setting and Participants}

Participants were between 15 and 80 y old, had WHO functional class III or IV with symptoms of PAH, and had been diagnosed with idiopathic PAH or chronic thromboembolism pulmonary hypertension. The diagnosis of idiopathic PAH and chronic thromboembolism pulmonary hypertension was established by ruling out other known causes according to criteria in current guidelines. ${ }^{16}$ For each participant, mean pulmonary artery pressure was required to be $\geq 25 \mathrm{~mm} \mathrm{Hg}$, and the pulmonary capillary wedge pressure was required to be $<15 \mathrm{~mm} \mathrm{Hg}$. Participants had not received previous treatment with an approved therapy for PAH before enrollment. Patients with acute pulmonary thromboembolism, left-sided heart diseases, pulmonary disease with $\mathrm{FEV}_{1} / \mathrm{FVC}<50 \%$ predicted or total lung capacity $<60 \%$, renal insufficiency, chronic liver disease, or portal hypertension were excluded from the study.

\section{Procedures}

Eligible participants were randomly assigned in a 1:1:1 ratio to receive bosentan and iloprost (combination therapy group), bosentan (bosentan monotherapy group), or iloprost (iloprost monotherapy group). Bosentan was administered at a dose of $62.5 \mathrm{mg}$ twice daily during the first month and then $125 \mathrm{mg}$ twice daily. Iloprost was administered at an increasing dose to a target of $10 \mu \mathrm{g} 4-6$ times/d (Fig. 1). 


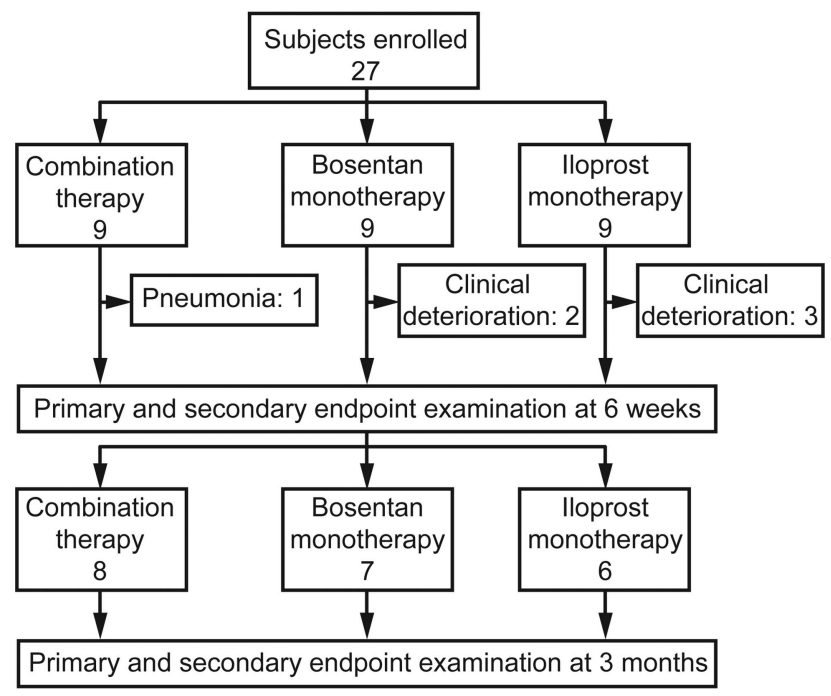

Fig. 1. Flow chart.

Discontinuation of monotherapy and initiation of combination therapy with bosentan and iloprost were performed in subjects whose condition deteriorated. The addition of phosphodiesterase type 5 inhibitors to the combination therapy regimen or discontinuation was performed in subjects whose condition deteriorated during combination therapy. These subjects were referred for lung transplantation. Efficacy and safety assessments were performed at the time of screening and at 6 weeks and 3 months after commencing treatment. Laboratory safety assessments were performed on a monthly basis.

\section{Outcome Measures}

The primary end point was changes in peak 6-min walk distance (6MWD) that were defined as within 10-60 min after iloprost inhalation at week 6 and 3 months after the initiation of treatment compared with baseline values. Prespecified secondary efficacy end points included changes in hemodynamic variables that were measured by right heart catheterization from baseline to 3 months after the initiation of treatment. Secondary efficacy end points also included changes in $\mathrm{N}$-terminal pro-brain natriuretic peptide (N-terminal pro-BNP) levels, WHO functional class, $\mathrm{P}_{\mathrm{aO}}$, and Minnesota Living with Heart Failure questionnaire scores from baseline to 6 weeks and 3 months after the initiation of treatment. Safety assessments included laboratory measurements and evaluation of adverse events.

\section{Statistical Analysis}

Statistical analyses were performed by the Department of Medical Statistics, Fourth Military Medical University. A sample size of 21 patients was calculated to detect a mean \pm SD difference of $50 \pm 50 \mathrm{~m}$ in the 6MWD from baseline to 6 weeks and 3 months after the initiation of treatment. Discontinuation of the study medication due to clinical deterioration before 6 weeks was not analyzed with the subject's assessment at the time of premature withdrawal. If no assessment was recorded, these patients were assigned with the worst rank value of $0 \mathrm{~m}$ for the $6 \mathrm{MWD}$, WHO functional class IV, the highest mean pulmonary artery pressure recording in the same patient population, the highest pulmonary capillary wedge pressure, the highest pulmonary vascular resistance, and the greatest decrease from baseline cardiac index to 3 months based on values from the same group. All other subjects without an assessment at 3 months had their last 6MWD and WHO functional class carried forward and were excluded from hemodynamic analysis.

Statistical analyses of differences among the groups in the 6MWD, Minnesota Living with Heart Failure questionnaire scores, $\mathrm{N}$-terminal pro- $\mathrm{BNP}, \mathrm{P}_{\mathrm{aO}_{2}}$, and cardiopulmonary hemodynamic measurements were performed using 3-sample one-way ANOVA and were verified with the Kruskal-Wallis test. Changes in WHO functional class from baseline to week 6 and 3 months after the initiation of treatment were analyzed using the Kruskal-Wallis test. The Tukey honest significant difference test was used in multiple comparisons if there was a significant difference among the treatment groups after analysis with one-way analysis of variance. The Nemenyi test was used in multiple comparisons if there was a significant difference in the WHO functional class among treatment groups after analysis with the KruskalWallis test. The difference in the proportion of subjects with adverse events among the 3 groups was analyzed using the Fisher exact test. With the exception of a prior planned analysis on the 6MWD test, which was confirmatory, all other analyses were exploratory. Statistical analyses were performed on an intention-to-treat basis. All $P$ values were 2-tailed.

\section{Results}

\section{Subject Demographics and Baseline Characteristics}

Twenty-seven subjects were enrolled at 4 centers between October 2012 and December 2015 and were randomized in a $1: 1: 1$ ratio to receive combination therapy orbosentan or iloprost monotherapy (Fig. 1). One subject prematurely withdrew from the combination therapy group due to severe pneumonia. Five subjects, comprising 2 subjects in the bosentan monotherapy group and 3 subjects in the iloprost monotherapy group, also prematurely withdrew from therapy due to clinical deterioration. Twentyone subjects were eligible to continue the study and comprised 18 subjects with idiopathic PAH and 3 with chronic thromboembolism pulmonary hypertension. Subject demo- 
Table 1. Demographic and Baseline Characteristics

\begin{tabular}{|c|c|c|c|c|}
\hline Characteristic & $\begin{array}{l}\text { Combination Therapy } \\
\text { Group }(n=8)\end{array}$ & $\begin{array}{c}\text { Bosentan Monotherapy } \\
\text { Group }(n=7)\end{array}$ & $\begin{array}{l}\text { Iloprost Monotherapy } \\
\text { Group }(n=6)\end{array}$ & $P$ \\
\hline Age, mean \pm SD y & $30.1 \pm 7.4$ & $39.4 \pm 5.2$ & $41.8 \pm 5.3$ & .39 \\
\hline Female sex, $n(\%)$ & $5(62.5)$ & $5(71.4)$ & $4(66.7)$ & .98 \\
\hline \multicolumn{5}{|l|}{ Coexisting conditions, $n(\%)$} \\
\hline Hypertension & $0(0)$ & $1(14.3)$ & $1(16.7)$ & .50 \\
\hline Diabetes & $0(0)$ & $1(14.3)$ & $0(0)$ & .62 \\
\hline Coronary artery disease & $1(12.5)$ & $0(0)$ & $1(16.7)$ & .73 \\
\hline \multicolumn{5}{|c|}{ Classification of pulmonary hypertension, $n(\%)$} \\
\hline Idiopathic & $7(87.5)$ & $5(71.4)$ & $6(100)$ & .60 \\
\hline СТЕРН & $1(12.5)$ & $2(28.6)$ & $0(0)$ & .75 \\
\hline \multicolumn{5}{|l|}{ Prior medications, $n(\%)$} \\
\hline Oxygen & $4(50)$ & $3(42.9)$ & $1(16.7)$ & .54 \\
\hline Anticoagulant & $3(37.5)$ & $1(14.1)$ & $2(33.3)$ & .71 \\
\hline Diuretic & $1(12.5)$ & $3(42.9)$ & $1(16.7)$ & .44 \\
\hline
\end{tabular}

$\overline{\mathrm{CTEPH}}=$ chronic thromboembolic pulmonary hypertension

Table 2. Disease Severity at Baseline

\begin{tabular}{|c|c|c|c|c|}
\hline Variable & $\begin{array}{l}\text { Combination Therapy } \\
\text { Group }(n=8)\end{array}$ & $\begin{array}{l}\text { Bosentan Monotherapy } \\
\text { Group }(n=7)\end{array}$ & $\begin{array}{l}\text { Iloprost Monotherapy } \\
\text { Group }(n=6)\end{array}$ & $P$ \\
\hline \multicolumn{5}{|l|}{ Hemodynamic variables } \\
\hline Mean pulmonary artery pressure, mean $\pm \mathrm{SD} \mathrm{mm} \mathrm{Hg}$ & $56.5 \pm 5.5$ & $54.0 \pm 1.7$ & $55.7 \pm 1.7$ & .90 \\
\hline Pulmonary vascular resistance, mean $\pm \mathrm{SD}$ dynes $/ \mathrm{s} / \mathrm{cm}^{5}$ & $1,038.0 \pm 175.8$ & $1,151.4 \pm 162.6$ & $1,157.3 \pm 165.3$ & .85 \\
\hline Cardiac output, mean $\pm \mathrm{SD}$ L/min & $4.19 \pm 0.45$ & $3.23 \pm 0.36$ & $3.50 \pm 0.49$ & .28 \\
\hline Cardiac index, mean $\pm \mathrm{SD} \mathrm{L} / \mathrm{min} / \mathrm{m}^{2}$ & $2.61 \pm 0.31$ & $1.94 \pm 0.18$ & $2.20 \pm 0.35$ & .25 \\
\hline NT-proBNP, mean \pm SD ng/L & $2,203.6 \pm 490.9$ & $2,110.4 \pm 251.1$ & $1,840.3 \pm 293.7$ & .80 \\
\hline 6-min walk distance, mean $\pm \mathrm{SD} \mathrm{m}$ & $300.3 \pm 36.2$ & $346.1 \pm 24.4$ & $330.8 \pm 37.1$ & .60 \\
\hline WHO functional class, $n(\%)$ & & & & .84 \\
\hline III & $5(62.5)$ & $5(71.4)$ & $5(83.3)$ & \\
\hline IV & $3(37.5)$ & $2(28.6)$ & $1(16.7)$ & \\
\hline MLWHF scores, mean \pm SD & $56.8 \pm 7.5$ & $67.7 \pm 3.6$ & $65.5 \pm 3.7$ & .35 \\
\hline $\mathrm{P}_{\mathrm{aO}_{2}}$, mean $\pm \mathrm{SD} \mathrm{mm} \mathrm{Hg}$ & $55.3 \pm 3.3$ & $57.5 \pm 2.6$ & $60.5 \pm 4.5$ & .59 \\
\hline \multicolumn{5}{|l|}{$\begin{array}{l}\text { NT-proBNP }=\text { N-terminal pro-brain natriuretic peptide } \\
\text { WHO = World Health Organization } \\
\text { MLWHF = Minnesota Living with Heart Failure }\end{array}$} \\
\hline
\end{tabular}

graphic data and baseline characteristics, including coexisting conditions, classification of $\mathrm{PAH}$, and prior medications, are described in Table 1 . There were no significant differences among the 3 groups for hemodynamic variables, N-terminal pro-BNP, 6MWD, WHO functional class, Minnesota Living with Heart Failure questionnaire scores, and $\mathrm{P}_{\mathrm{aO}_{2}}$ value (Table 2).

\section{Primary Efficacy End Point}

Changes in 6MWD results are presented in Figure 2 and Table 3. Changes in peak 6MWD from baseline to week 6 were significantly different among the 3 groups $(P=.001)$ with $95.6 \pm 20.3 \mathrm{~m}$ for the combination therapy group,
$1.3 \pm 10.9 \mathrm{~m}$ for the bosentan monotherapy group, and $-0.67 \pm 15.8 \mathrm{~m}$ for the iloprost monotherapy group (Table 3).There was a significant difference $(P<.001)$ in changes in the peak 6MWD from baseline to 3 months among the 3 groups. An increase of $133.75 \pm 25.6 \mathrm{~m}$ was observed in subjects receiving combination therapy, $0.86 \pm 17.6 \mathrm{~m}$ in subjects receiving bosentan monotherapy, and $10.2 \pm 20.0 \mathrm{~m}$ in subjects receiving iloprost monotherapy (Table 3).

\section{Secondary Efficacy End Points}

There was no difference in changes in pulmonary vascular resistance $(P=.62)$ and cardiac output $(P=.074)$ from baseline to 3 months among the 3 groups (Table 3 ). 


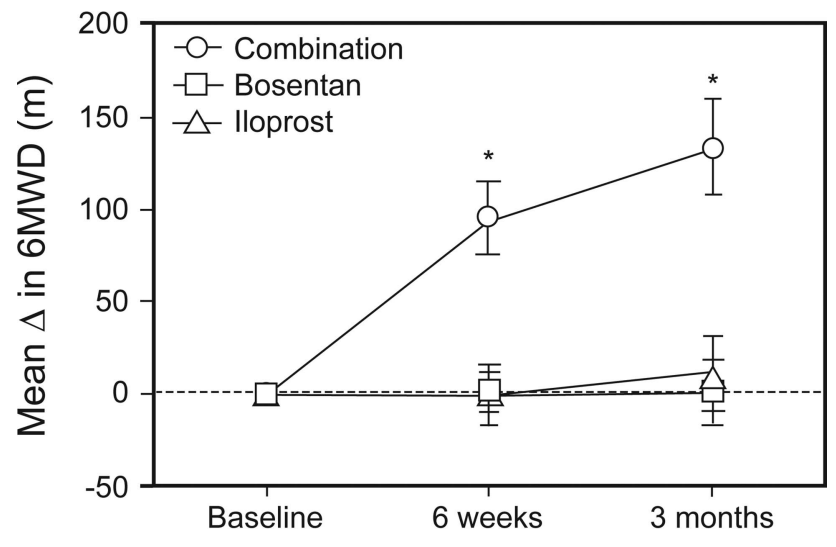

Fig. 2. Changes in 6-min walk distance (6MWD) after treatment. Following 6 weeks and 3 months of treatment, changes in 6MWD from baseline values were significantly different among the 3 groups. The 6MWD significantly increased in the combination therapy group compared with the bosentan and iloprost monotherapy groups. *, $\mathrm{P}<.001$.

There were significant differences in changes of mean pulmonary artery pressure $(-18.9 \pm 2.8 \mathrm{~mm} \mathrm{Hg}$ for combination therapy, $-2.0 \pm 3.5 \mathrm{~mm} \mathrm{Hg}$ for bosentan monotherapy, and $-4.0 \pm 3.5 \mathrm{~mm} \mathrm{Hg}$ for iloprost monotherapy, $P=.002)$ and cardiac index $(0.55 \pm 0.20,0.07 \pm 0.16$, and $-0.09 \pm 0.15 \mathrm{~L} / \mathrm{min} / \mathrm{m}^{2}$, respectively, $P=.041$ ) from baseline to 3 months among the 3 groups (Table 3 ). Nterminal pro-BNP in the combination therapy group significantly decreased at both week $6(P=.03)$ and 3 months $(P=.01)$ compared with the monotherapy groups (Table 3 ). Changes in WHO functional class were observed from baseline to week 6 in the combination therapy group but were not significantly different compared with the monotherapy groups $(P=.054)$ (Table 4$)$. Significant changes in WHO functional class from baseline to 3 months were found in the combination therapy group compared with the monotherapy groups $(P=.003)$, with $62.5 \%$ of combination therapy subjects classified as class I and the remaining $37.5 \%$ as class II (Table 4). Changes in the $\mathrm{P}_{\mathrm{aO}}$ values were significantly increased from baseline to week 6 $(P=.004)$ and 3 months $(P=.004)$ compared with the monotherapy groups (Table 3 ). Quality of life significantly improved in the combination therapy group compared with the monotherapy groups, with Minnesota Living with Heart Failure questionnaire scores decreasing at week $6(P<.001)$ and 3 months $(P=.002)$ (Table 3$)$.

\section{Safety}

Adverse events are summarized in Table 5 and include headache, cough, flushing, chest pain, nausea, dizziness, palpitations, peripheral edema, fatigue, exacerbated dyspnea, and abdominal distention. There were no significant differences in the incidence of adverse events in the com- bination therapy group (87.5\%) compared with the bosen$\tan$ monotherapy group (71.4\%) and iloprost monotherapy group $(83.3 \%)(P=.80)$. The most common adverse events in subjects were headache, fatigue, and exacerbated dyspnea, and they occurred in $33.3 \%$ of subjects receiving iloprost monotherapy (Table 5). In the combination therapy group, the most common adverse event was flushing (25.0\%), whereas cough (28.6\%) and exacerbated dyspnea (28.6\%) were most common in the bosentan monotherapy group. There were no serious adverse events reported in the 3 groups that resulted in premature discontinuation from the study.

\section{Discussion}

This randomized study was performed to compare the efficacy of initial combination therapy using bosentan and iloprost with individual monotherapy in the treatment of PAH. We found that initial combination therapy in treatment-naive PAH subjects with WHO functional class III or IV can significantly improve 6MWD, hemodynamics, and quality of life compared with monotherapy. This smallsample size, open-label study provides a basis for larger, randomized blinded trials.

The REVEAL registry study reported that 60 and $16 \%$ of subjects in the PAH-related death cohort were of WHO functional class III and IV, respectively. ${ }^{9} \mathrm{Com}-$ bination therapy was not consistently used in the most seriously ill subjects enrolled in the REVEAL study after being assessed as WHO functional class IV or at the time of death, and only $57.7 \%$ of these subjects were treated with intravenous prostacyclin. ${ }^{9}$ The REVEAL study found that PAH subjects with WHO functional class III and IV were not provided with sufficient treatment, and rescuing subjects with PAH whose condition markedly deteriorates is rather difficult. Thus, sequential add-on combination therapy may be too late for such patients with WHO functional class III and IV. The AMBITION study is the first to compare the use of upfront combination therapy in subjects with treatmentnaive incident $\mathrm{PAH}$ who were randomized to therapy with ambrisentan plus tadalafil versus ambrisentan or tadalafil monotherapy. ${ }^{15}$ The study concluded that initial combination therapy with ambrisentan and tadalafil results in a significantly lower risk of clinical failure events than the risk with ambrisentan or tadalafil monotherapy. ${ }^{15}$ Thus, the AMBITION study presented a new treatment paradigm for $\mathrm{PAH}$. In the present study, $\mathrm{PAH}$ subjects with WHO functional class III or IV were randomized and treated using first-line upfront therapy with bosentan and iloprost and first-line bosentan and iloprost monotherapy.

Both patients and doctors should consider the financial burden of first-line upfront combination therapy. Upfront combination therapy for $\mathrm{PAH}$ is expensive for both the 
Table 3. Primary and Secondary Efficacy End Points

\begin{tabular}{|c|c|c|c|c|}
\hline End Points & $\begin{array}{l}\text { Combination Therapy } \\
\text { Group }(n=8)\end{array}$ & $\begin{array}{l}\text { Bosentan Monotherapy } \\
\text { Group }(n=7)\end{array}$ & $\begin{array}{l}\text { Iloprost Monotherapy } \\
\text { Group }(n=6)\end{array}$ & $P$ \\
\hline \multicolumn{5}{|l|}{ Primary end point } \\
\hline \multicolumn{5}{|l|}{ Change in 6-min walk distance, mean $\pm \mathrm{SD} \mathrm{m}$} \\
\hline 6 weeks & $95.6 \pm 20.3$ & $1.3 \pm 10.9$ & $-0.67 \pm 15.8$ & .001 \\
\hline 3 months & $133.75 \pm 25.6$ & $0.86 \pm 17.6$ & $10.2 \pm 20.0$ & $<.001$ \\
\hline \multicolumn{5}{|l|}{ Secondary end points } \\
\hline \multicolumn{5}{|l|}{ Change in hemodynamic variables ( 3 months) } \\
\hline Mean pulmonary artery pressure, mean $\pm \mathrm{SD} \mathrm{mm} \mathrm{Hg}$ & $-18.9 \pm 2.8$ & $-2.0 \pm 3.5$ & $-4.0 \pm 3.5$ & .002 \\
\hline Pulmonary vascular resistance, mean $\pm \mathrm{SD}$ dynes $/ \mathrm{s} / \mathrm{cm}^{5}$ & $-186.5 \pm 174.6$ & $-164.4 \pm 169.7$ & $40.2 \pm 161.0$ & .62 \\
\hline Cardiac output, mean $\pm \mathrm{SD}$ L/min & $0.84 \pm 0.32$ & $0.12 \pm 0.25$ & $-0.08 \pm 0.25$ & .07 \\
\hline Cardiac index, mean $\pm \mathrm{SD} \mathrm{L} / \mathrm{min} / \mathrm{m}^{2}$ & $0.55 \pm 0.20$ & $0.07 \pm 0.16$ & $-0.09 \pm 0.15$ & .041 \\
\hline \multicolumn{5}{|l|}{ Change in NT-proBNP, mean $\pm \mathrm{SD}$ ng/L } \\
\hline 6 weeks & $-918.9 \pm 246.8$ & $-114.1 \pm 233.5$ & $-158.6 \pm 99.2$ & .03 \\
\hline 3 months & $-1,400.9 \pm 457.1$ & $144.4 \pm 207.9$ & $-13.6 \pm 191.3$ & .01 \\
\hline \multicolumn{5}{|l|}{ Change in MLWHF } \\
\hline 6 weeks & $-25.6 \pm 3.4$ & $-5.6 \pm 3.9$ & $-0.17 \pm 3.3$ & $<.001$ \\
\hline 3 months & $-37.0 \pm 7.3$ & $-6.9 \pm 15.9$ & $-1.7 \pm 5.9$ & .002 \\
\hline \multicolumn{5}{|l|}{ Change in $\mathrm{P}_{\mathrm{aO}}$, mean $\pm \mathrm{SD} \mathrm{mm} \mathrm{Hg}$} \\
\hline 6 weeks & $14.4 \pm 2.4$ & $3.4 \pm 3.1$ & $1.0 \pm 2.2$ & .004 \\
\hline 3 months & $18.4 \pm 3.2$ & $3.4 \pm 3.9$ & $1.6 \pm 3.1$ & .004 \\
\hline
\end{tabular}

Table 4. Changes in World Health Organization Functional Class From Baseline to Week 6 and 3 Months After Initiation of Treatment

\begin{tabular}{|c|c|c|c|c|c|c|c|c|c|c|c|c|c|}
\hline \multirow{2}{*}{ Time } & \multicolumn{3}{|c|}{ FC I } & \multicolumn{3}{|c|}{ FC II } & \multicolumn{3}{|c|}{ FC III } & \multicolumn{3}{|c|}{ FC IV } & \multirow{2}{*}{$P$} \\
\hline & 1 & 2 & 3 & 1 & 2 & 3 & 1 & 2 & 3 & 1 & 2 & 3 & \\
\hline Baseline, \% & & & & & & & 62.5 & 71.4 & 83.3 & 37.5 & 28.6 & 16.7 & .84 \\
\hline 6 weeks, $\%$ & & & & 75.0 & 28.6 & 33.3 & 25.0 & 71.4 & 33.3 & 0 & 0 & 33.3 & .054 \\
\hline 3 months, $\%$ & 62.5 & 0 & 0 & 37.5 & 42.9 & 33.3 & 0 & 42.9 & 50.0 & 0 & 14.3 & 16.7 & .003 \\
\hline \multicolumn{14}{|c|}{$\begin{array}{l}1=\text { combination therapy group }(n=8) \\
2=\text { bosentan monotherapy group }(n=7) \\
3=\text { iloprost monotherapy group }(n=6) \\
\text { FC }=\text { functional class }\end{array}$} \\
\hline
\end{tabular}

patient and health-care providers. There is indeed a cogent pharmacoeconomic argument for upfront combination therapy: If patients with PAH are at high risk of immediate clinical deterioration or death, first-line upfront combination therapy should be preferred. PAH patients and their physicians should discuss the balance between the benefits of reducing the risk of clinical deterioration and the pharmacoeconomic costs.

The issue of drug-drug interactions, which may affect the pharmacokinetic profile of both agents in combination therapy, has great implications for adverse effects and efficacy, with a spectrum of possible outcomes that include synergism, additive effects, and possibly even antagonism. Bosentan is an inducer of cytochrome P450 isoenzymes CYP3A4 and CYP2C9. ${ }^{17}$ Coadministration of bosentan reduces plasma concentrations of drugs metabolized by these isoenzymes. Bosentan is also metabolized by CYP3A4 and CYP2C9; therefore, their inhibition may increase the plasma concentration of bosentan. Sildenafil is a substrate of CYP3A4, and, when used in combination with bosentan, its levels decrease by $50 \%$ whereas bosen$\tan$ levels increase by $50 \%$, and dose adjustments of either drug may not be required. ${ }^{16,18,19}$ Bosentan and iloprost inhalation have no drug-drug interactions with respect to pharmacokinetics. ${ }^{20}$ Iloprost, a vasodilator and stable analog of prostacyclin, confers great benefit through vasodilatation, antiproliferative effects, and inhibition of platelet aggregation. ${ }^{21}$ Bosentan, an oral nonspecific endothelin receptor antagonist with dual activity on both endothelin type A and B receptors, improves the overall quality of life 
Table 5. Adverse Events

\begin{tabular}{lccc}
\hline \hline \multirow{1}{*}{ Variable } & \multicolumn{3}{c}{ Subjects, $n(\%)$} \\
\cline { 2 - 4 } & $\begin{array}{c}\text { Combination } \\
\text { Therapy } \\
\text { Group }(n=8)\end{array}$ & $\begin{array}{c}\text { Bosentan } \\
\text { Monotherapy } \\
\text { Group }(n=7)\end{array}$ & $\begin{array}{c}\text { Iloprost } \\
\text { Monotherapy } \\
\text { Group }(n=6)\end{array}$ \\
\hline Any adverse events* & $7(87.5)$ & $5(71.4)$ & $5(83.3)$ \\
Headache & $1(12.5)$ & $0(0)$ & $2(33.3)$ \\
Cough & $1(12.5)$ & $2(28.6)$ & $1(16.7)$ \\
Flushing & $2(25.0)$ & $0(0)$ & $1(16.7)$ \\
Chest pain & $0(0)$ & $0(0)$ & $1(16.7)$ \\
Nausea & $1(12.5)$ & $1(13.3)$ & $0(0)$ \\
Dizziness & $1(12.5)$ & $0(0)$ & $0(0)$ \\
Palpitations & $1(12.5)$ & $1(13.3)$ & $1(16.7)$ \\
Peripheral edema & $1(12.5)$ & $0(0)$ & $1(16.7)$ \\
Fatigue & $1(12.5)$ & $1(14.3)$ & $2(33.3)$ \\
Exacerbated dyspnea & $1(12.5)$ & $2(28.6)$ & $2(33.3)$ \\
Abdominal distention & $0(0)$ & $1(13.3)$ & $1(16.7)$ \\
* Fisher exact probability. $P=.80$. & & \\
\hline
\end{tabular}

in patients. ${ }^{22,23}$ The add-on sequential combination therapy study of bosentan and iloprost demonstrated that the addition of inhaled iloprost to bosentan monotherapy in subjects with PAH with reduced exercise capacity is safe and efficacious in increasing 6MWD. ${ }^{24}$ Subjects with bosentan-refractory PAH have been successfully treated following the addition of inhaled iloprost. ${ }^{25}$ These sequential combination therapy studies provide evidence for the synergistic or additive effects between bosentan and iloprost, which were further demonstrated by the results of the present study. Initial combination therapy with bosentan and iloprost in PAH patients with WHO functional class III or IV can significantly improve 6MWD, hemodynamics, and quality of life compared with bosentan or iloprost monotherapy.

In the AMBITION trial, the primary end point was the time to the first clinical failure event. The first clinical failure event was defined as the first occurrence of a composite of death, hospitalization for deteriorating PAH, disease progression, or unsatisfactory long-term clinical response. ${ }^{15}$ Short-term studies are required to identify the instant efficacy of treatment regimens. In the present study, the primary end points were changes in 6MWD, and the secondary end points were changes in hemodynamic variables, N-terminal pro-BNP, WHO functional class, $\mathrm{P}_{\mathrm{aO}_{2}}$, and Minnesota Living with Heart Failure questionnaire scores. All of the aforementioned variables are able to reflect the instant efficacy of the treatment regimen and are easily detectable in clinical practice.

Due to the small sample size and open-label nature of this study, additional studies with large samples and placebo controls are required to further assess the treatment efficacy and the tolerability of initial combination therapy in PAH. This study only demonstrates a trend of efficacy for initial combination therapy in subjects with PAH and provides a clue for future trials.

\section{Conclusions}

In this study, first-line upfront combination therapy using bosentan and iloprost in PAH subjects with WHO functional class III or IV can significantly improve 6MWD, hemodynamics, and quality of life compared with monotherapy comprising bosentan or iloprost. Due to the limitations of this study, additional trials are required to further confirm the treatment efficacy of initial combination therapy in PAH.

\section{REFERENCES}

1. Galiè N, Manes A, Branzi A. Prostanoids for pulmonary arterial hypertension. Am J Respir Med 2003;2(2):123-137.

2. Dupuis J, Hoeper MM. Endothelin receptor antagonists in pulmonary arterial hypertension. Eur Respir J 2008;31(2):407-415.

3. Arif SA, Poon H. Tadalafil: a long-acting phosphodiesterase-5 inhibitor for the treatment of pulmonary arterial hypertension. Clin Ther 2011;33(8):993-1004.

4. Enderby CY, Burger C. Medical treatment update on pulmonary arterial hypertension. Ther Adv Chronic Dis 2015;6(5):264-272.

5. Hambly N, Granton J. Riociguat for the treatment of pulmonary hypertension. Expert Rev Respir Med 2015;9(6):679-695.

6. Skoro-Sajer N, Lang IM. Selexipag for the treatment of pulmonary arterial hypertension. Expert Opin Pharmacother 2014;15(3):429436.

7. MacKenzie AM, Peacock AJ. Medical therapies for the treatment of pulmonary arterial hypertension: how do we choose? Curr Hypertens Rep 2015;17(7):56-

8. Galiè N, Humbert M, Vachiery JL, Gibbs S, Lang I, Torbicki A, et al. 2015 ESC/ERS Guidelines for the diagnosis and treatment of pulmonary hypertension: the Joint Task Force for the Diagnosis and Treatment of Pulmonary Hypertension of the European Society of Cardiology (ESC) and the European Respiratory Society (ERS): endorsed by: Association for European Paediatric and Congenital Cardiology (AEPC), International Society for Heart and Lung Transplantation (ISHLT). Eur Respir J 2015;46(4):903-975.

9. Farber HW, Miller DP, Meltzer LA, McGoon MD. Treatment of patients with pulmonary arterial hypertension at the time of death or deterioration to functional class IV: insights from the REVEAL Registry. J Heart Lung Transplant 2013;32(11):1114-1122.

10. Hirashiki A, Kondo T, Murohara T. Combination therapy adding tadalafil to existing ambrisentan in patients with pulmonary arterial hypertension. Hypertens Res 2014;37(6):488-489.

11. Channick RN, Olschewski H, Seeger W, Staub T, Voswinckel R, Rubin LJ. Safety and efficacy of inhaled treprostinil as add-on therapy to bosentan in pulmonary arterial hypertension. J Am Coll Cardiol 2006;48(7):1433-1437.

12. Levy M, Celermajer DS, Bourges-Petit E, Del Cerro MJ, Bajolle F, Bonnet D. Add-on therapy with subcutaneous treprostinil for refractory pediatric pulmonary hypertension. J Pediatr 2011;158(4):584588 .

13. Douwes JM, Roofthooft MT, Van Loon RL, Ploegstra MJ, Bartelds B, Hillege HL, Berger RM. Sildenafil add-on therapy in paediatric pulmonary arterial hypertension, experiences of a national referral centre. Heart 2014;100(3):224-230. 


\section{INITIAL COMBINATION THERAPY FOR PAH}

14. Jacobs W, Boonstra A, Marcus JT, Postmus PE, Vonk-Noordegraaf A. Addition of prostanoids in pulmonary hypertension deteriorating on oral therapy. J Heart Lung Transplant 2009;28(3):280-284.

15. Galiè N, Barberà JA, Frost AE, Ghofrani HA, Hoeper MM, McLaughlin $\mathrm{VV}$, et al. Initial use of ambrisentan plus tadalafil in pulmonary arterial hypertension. N Engl J Med 2015;373(9):834-844.

16. Galiè N, Hoeper MM, Humbert M, Torbicki A, Vachiery JL, Barbera $\mathrm{JA}$, et al. Guidelines for the diagnosis and treatment of pulmonary hypertension: the Task Force for the Diagnosis and Treatment of Pulmonary Hypertension of the European Society of Cardiology (ESC) and the European Respiratory Society (ERS), endorsed by the International Society of Heart and Lung Transplantation (ISHLT). Eur Heart J 2009;30(20):2493-2537.

17. Dingemanse J, van Giersbergen PL. Clinical pharmacology of bosentan, a dual endothelin receptor antagonist. Clin Pharmacokinet 2004; 43(15):1089-1115.

18. Weiss J, Theile D, Spalwisz A, Burhenne J, Riedel KD, Haefeli WE. Influence of sildenafil and tadalafil on the enzyme- and transporterinducing effects of bosentan and ambrisentan in LS180 cells. Biochem Pharmacol 2013;85(2):265-273.

19. Task Force for Diagnosis and Treatment of Pulmonary Hypertension of European Society of Cardiology (ESC), European Respiratory
Society (ERS), International Society of Heart and Lung Transplantation (ISHLT), Galiè N, Hoeper MM, Humbert M, et al. Guidelines for the diagnosis and treatment of pulmonary hypertension. Eur Respir J 2009;34(6):1219-1263.

20. Austin MJ, McDougall NI, Wendon JA, Sizer E, Knisely AS, Rela $\mathrm{M}$, et al. Safety and efficacy of combined use of sildenafil, bosentan, and iloprost before and after liver transplantation in severe portopulmonary hypertension. Liver Transpl 2008;14(3):287-291.

21. Baker SE, Hockman RH. Inhaled iloprost in pulmonary arterial hypertension. Ann Pharmacother 2005;39(7):1265-1274.

22. Rubin LJ, Badesch DB, Barst RJ, Galie N, Black CM, Keogh A, et al. Bosentan therapy for pulmonary arterial hypertension. N Engl J Med 2002;346(12):896-903.

23. Saleh JA. Role of iloprost and bosentan in pulmonary arterial hypertension. Niger J Med 2008;17(1):13-19.

24. McLaughlin VV, Oudiz RJ, Frost A, Tapson VF, Murali S, Channick $\mathrm{RN}$, et al. Randomized study of adding inhaled iloprost to existing bosentan in pulmonary arterial hypertension. Am J Respir Crit Care Med 2006;174(11):1257-1263.

25. Ahmadi-Simab K, Lamprecht P, Gross WL. Successful therapy of bosentan-refractory pulmonary arterial hypertension (PAH) with inhalative iloprost. Clin Exp Rheumatol 2005;23(3):402-403. 